\title{
Quantitative Electroencephalographic Changes and Retinal Alterations in Subclinical Cerebrovascular Injury: A Case Report
}

\author{
Brown-Martínez $\mathbf{M}^{1 *}$, Virués $T^{1}$, Valdés $\mathbf{Y}^{2}$, \\ González $E^{2}$, Fernández $O^{3}$, Hernández $Z^{4}$, \\ Constanten $Y^{5}$, Galán $L^{1}$ and Despaigme $E^{2}$ \\ ${ }^{1}$ Department of Neurophysiology, Cuban Neuroscience \\ Center, Cuba \\ ${ }^{2}$ Research Departments, University Hospital General \\ Calixto García, Cuba \\ ${ }^{3}$ Department of Ophthalmology, University Hospital \\ General Calixto García, Cuba \\ ${ }^{4}$ Department of Radiology, Institute of Neurology and \\ Neurosurgery, Cuba \\ ${ }^{5}$ Department of Ophthalmology, Luis Díaz Soto Hospital, \\ Cuba \\ *Corresponding author: Brown-Martínez M, \\ Department of Neurophysiology, Cuban Neurosciences \\ Center, Ave 25 N0 15007 esq. 158. Apartado 6412. \\ Cubanacán. Playa, La Habana, Cuba
}

Received: May 11, 2017; Accepted: J une 12, 2017; Published: June 23, 2017

\begin{abstract}
Small vessel disease induced by arterial hypertension is associated with an increased risk of stroke, dementia, cognitive impairment, and death. It comprises a group of lesions visible only by magnetic resonance imaging technique, which cannot be used in a comprehensive evaluation of hypertensive patient because of its cost and availability. We present an uncontrolled hypertensive patient with cardiovascular risk factors, with no history of previous cerebro vascular events presenting signs of small vessel disease on brain resonance imaging. Evident signs of hypertensive retinopathy in both eyes were observed, with micro hemorrhage and micro exudates in the left eye. Quantitative electroencephalographic analysis showed a significant increase in theta frequency, predominantly in left frontal, central and temporal regions. These findings could indicate the potential of these simpler and economical methods, in the prediction of subclinical brain damage of hypertensive patients.

Keywords: Stroke; Retina; Electroencephalogram; Biomarker; Arterial hypertension
\end{abstract}

\section{Abbreviations}

SVD: Small Vessel Disease; AH: Arterial Hypertension; MRI: Magnetic Resonance Imaging; EEG: Electroencephalogram; ME: Micro Exudate; MH: Micro Hemorrhage; WML: White Matter Lesions; FLAIR: Fluid-Attenuated Inversion Recovery

\section{Introduction}

Arterial Hypertension (AH) is estimated to about $12.8 \%$ of the total annual deaths. It is the most prevalent disease affecting about 1 billion people worldwide, and is one of the most important risk factors for cerebral ischemia and intracerebral hemorrhage development [1]. Beyond those well-known effects, $\mathrm{AH}$ is associated with the risk of asymptomatic brain damage identified in magnetic resonance imaging (MRI) images by lesions such as lacunar infarcts, white matter lesions (WML), perivascular spaces dilatation, and microbleeds [2]. These lesions are expressions of cerebral small vessel disease (SVD) induced and accelerated by AH. They course subclinically for long periods promoting cognitive and silent structural abnormalities that precede the final complication.

Neither the availability nor the cost of MRI studies allow its wide use to assess subclinical brain injury, contrary to the ease identification of subclinical damage to another target organs such as heart, by means of electrocardiogram or echocardiogram, and kidney, through blood creatinine or microalbuminuria tests [2]. Therefore, the early detection of cerebrovascular subclinical lesions is currently an unsolved problem in medical practice, which drives the search for useful tools that allow the early identification of such brain lesions. The aim of this work is to illustrate the usefulness of the information contained in the electroencephalogram (EEG) and retinal digital images for the prediction of asymptomatic cerebrovascular lesions related to $\mathrm{AH}$.

\section{Case Presentation}

A 49-year-old hypertensive woman, obese, sedentary, non-smoker, with no history of other chronic diseases or previous cerebro vascular events, refers difficult control of the hypertension accompanied by occasional frontal headache. On physical examination were found an increase in blood pressure $(180 / 110 \mathrm{mmHg})$, and body mass index $\left(30.6 \mathrm{~kg} / \mathrm{m}^{2}\right)$. The neurological examination was negative, with a total mental mini exam score of 26 and a decreased performance in the items of calculation/attention, and language.

Blood chemistry test showed alterations in fasting $(7 \mathrm{mmol} / \mathrm{L})$ and postprandial $(11.7 \mathrm{mmol} / \mathrm{L})$ glycemia, diagnosing Diabetes Mellitus type 2; Quantitative microalbuminuria $(27.23 \mathrm{mg} / \mathrm{L})$, with a borderline atherogenic index [3-9]. Ambulatory blood pressure monitoring reflected uncontrolled hypertension with high mean systolic and diastolic pressures in the daytime period (167/110 $\mathrm{mmHg}$ ), nocturnal (152/97 mmHg), and during 24 hours (164/108 $\mathrm{mmHg}$ ), high pressure loads at $100 \%$ and increased arterial stiffness, with a mean pulse pressure of $56 \mathrm{mmHg}$ and a non-dipper circadian pattern.

Scans were obtained on a 3.0-T scanner (Siemens, MAGNETOM Concerto, Germany). The protocol included T1-weighted tridimensional (3D), T2-weighted 3D, T2*weighted gradientrecalled echo and axial fluid-attenuated inversion recovery (FLAIR) sequences. A rounded hyperintense signal of approximately $5 \mathrm{~mm}$ in
Austin J Cerebrovasc Dis \& Stroke - Volume 4 Issue 4 - 2017 ISSN : 2381-9103 | www.austinpublishing group.com Brown-Martínez et al. (C) All rights are reserved
Citation: Brown-Martínez M, Virués T, Valdés Y, González E, Fernández O, Hernández Z, et al. Quantitative Electroencephalographic Changes and Retinal Alterations in Subclinical Cerebrovascular Injury: A Case Report. Austin J Cerebrovasc Dis \& Stroke. 2017; 4(4): 1065 

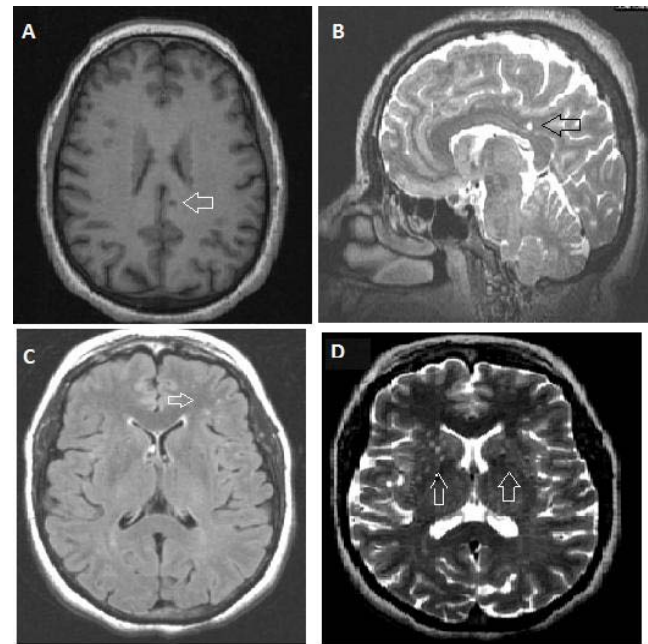

Figure 1: Brain scans showing: (A) a rounded hypointense signal on axial T1 3D sequence, localized in subcortical white matter close to the posterior cingulate, compatible with lacunar infarction; (B) the same lesion, hyperintense on sagittal T2 3D; (C) Multiple frontal white matter hyperintensities, predominantly left on axial FLAIR sequence and (D) perivascular spaces dilated at basal nuclei.

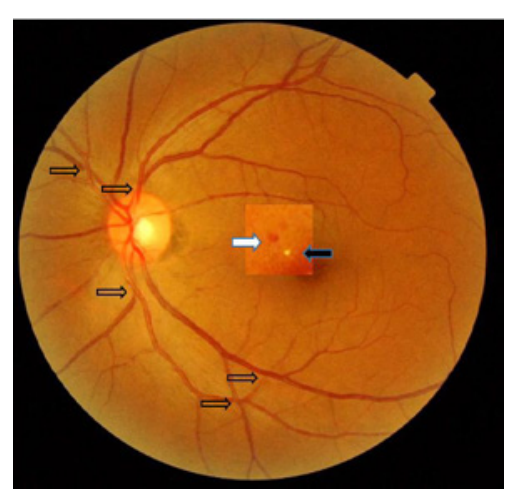

Figure 2: Retinal digital image showing grade III hypertensive retinopathy in the left eye reflecting multiple arteriovenous crosses (transparent arrows), micro exudate (black arrow) and micro hemorrhage (white arrow).

diameter was observed in the left parietal region of vascular origin compatible with lacunar infarction, as well as multiple subcortical hyperintense lesions, mainly frontal and periventricular, and Virchow Robins spaces dilated at basal nuclei (Figure 1).

Direct ophthalmoscopy and retinal digital images of both eyes (Topcon Mydriatic Eye Fund Camera-TRC-50EX) showed signs of grade II hypertensive retinopathy such as arteriolar narrowing and arteriovenous nicking in both eyes. In the left eye, two small lesions, a micro exudate and a micro hemorrhage $(\mathrm{ME}$ and $\mathrm{MH})$ were also observed, so grade III hypertensive retinopathy was diagnosed in the left eye [3] (Figure 2).

The EEG recordings (MEDICID-04 System, Neuronic S.A.) was made using 10/20 international system and standard procedures described elsewhere [4]. It reflected an increase in slow (theta frequency) activity predominantly localized in left frontal, center and temporal regions, with a maximum at $6.2 \mathrm{~Hz}$. It was interpreted as probable subcortical origin, due to its reactivity to ocular opening.

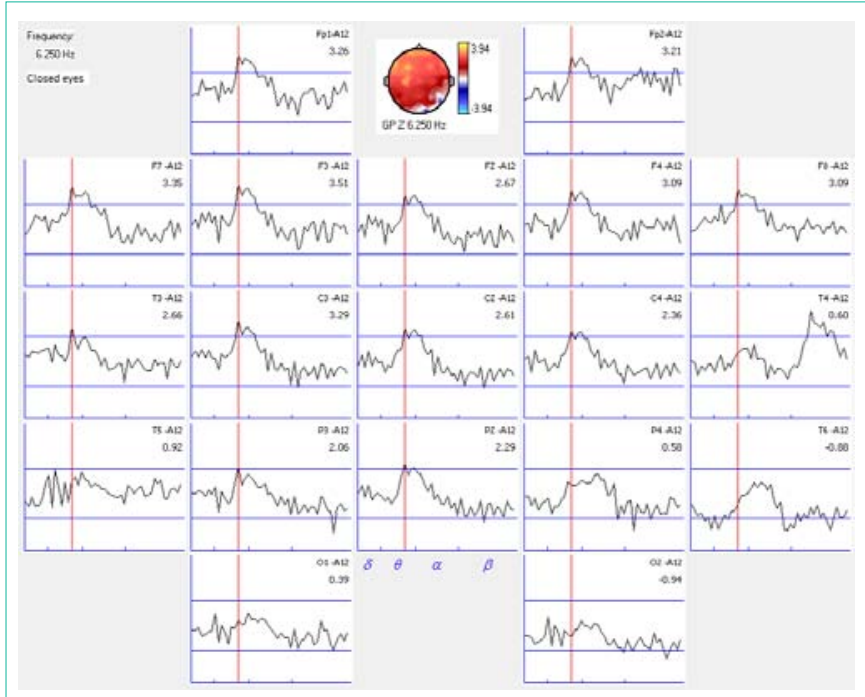

Figure 3: Quantitative EEG analisys showing a significative increase in thetha activity $(6.2 \mathrm{~Hz})$ on frontal, central and temporal derivations at rest, mainly on left hemisphere.

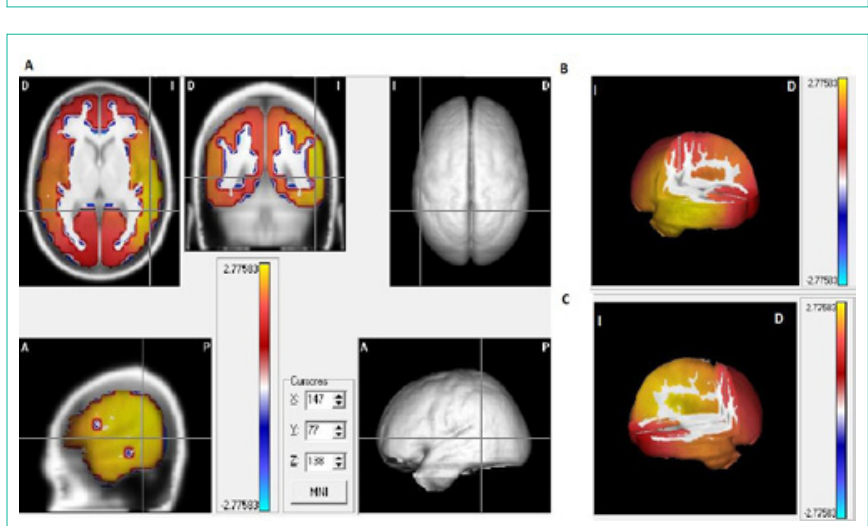

Figure 4: Electric brain tomographic showing theta activity sources exceeding 2.5 standard deviations. (A) Orthogonal planes. (B,C) Tridimensional representation of the increased theta activity mainly at left hemisphere in medial and temporal regions. (B) Tomographic section of medial, lateral and posterior regions on left hemisphere. (C) Tomographic section of homologous regions on right hemisphere.

For quantitative EEG analysis, we applied Fast Fourier Transform method to twenty segments of $2.56 \mathrm{sec}$. duration at closed eyes state, free of artifact and state's changes, selected by an expert electroencephalographer, through visual inspection (Figure 3). Source Localizer software (Neuronic SA) was used for the estimation of current sources using Low Resolution Electrical Tomography method [5] and the Montreal Neurological Institute probabilistic brain atlas. We obtained a 3D map of $\mathrm{Z}$ values for $6.2 \mathrm{~Hz}$ sources on axial, sagittal and coronal slices of $1 \mathrm{~mm}$ each, showing more than 2.5 standard deviation at this frequency in the left hemisphere mainly at temporal region (Figure 4).

\section{Discussion and Conclusion}

Chronic AH induces vascular remodeling that determines structural changes in cerebral vessels favoring the appearance of cerebral SVD. It has a subclinical course for long periods, causing lesions such as lacunar infarcts, white matter lesions, and microbleeds. 
WML are visualized on MRI as hyperintense signals in T2-weighted images (including FLAIR images), while lacunar infarcts correspond to small lesions with a diameter ranging from 3 to $15 \mathrm{~mm}$ with signal intensity comparable to that of localized cerebrospinal fluid present in white substance or subcortical gray matter [6]. Microbleeds are visualized as small hypointense rounded foci observed in $\mathrm{T} 22^{*}$ susceptibility images in echo gradient sequences, mostly located in the basal ganglia or in cortical or subcortical areas [7]. In this patient, we found on MRI a small cavitated lacunar infarct close to posterior cingulus region and multiple subcortical WML at frontal lobe and periventricular areas, as expression of SVD.

Several studies have pointed out that these lesions are much more prevalent than other target organs lesions induced by $\mathrm{AH}$ and that they frequently occur in absence of demonstrable damage in other target organs [8-10]. In these cases, stratification of cardiovascular risk is not faithful, since it requires the identification of target organs lesions [11]. This limitation can lead to insufficient patient management. However, even in countries with big resources, it is not possible to use MRIs for early identification of silent cerebral lesions. Therefore, there is an unmet need for biomarkers or predictors of SVD that can be used in medical practice [12].

The local and superficial nature of the electrical potentials recorded by the EEG has made it a very useful technique in the differentiated exploration of the functional status of each cortical region. Previous works have proposed EEG neurophysiological markers for cerebrovascular damage including general parameters of EEG and specific indices as alfa3/alfa2 ratio, and theta/alpha1 ratio in subjects with mild cognitive impairment and Alzheimer disease [13-15]. However, few evidence has arisen from neurological asymptomatic hypertensive patients.

In the current case, we were able to map an increase in theta frequency with the use of quantitative EEG parameters obtained from a conventional array. This change could be explained on the bases of cortico-subcortical fibers disruption by subcortical cerebrovascular lesions [14]. It has been pointed out that axonal delay and synaptic times of these fibers determine the EEG frequencies and that fiber myelination affects the speed propagation along cortical fibers. This parameter is strictly correlated to the frequency range recorded on the scalp [16]. Based in these reports, we thought that lacunar infarct present in this patient, as well as the WML, can cause the EEG changes founded, which not necessarily identify the exact localization of these lesion, but could predict its presence and perhaps its intensity.

Another important aspect to consider is the proximity of lacunar lesion to the posterior cingulate cortex, which may affect its function. The posterior cingulate cortex has prominent connections to the frontal lobes, specially the dorsal region of posterior cingulate cortex. Although there is not clear consensus about its function some evidence suggests that may play a direct role in regulating focus of attention [17]. Therefore, it can be an explanation for cognitive alterations found in this patient mainly in calculation and attention capacities. The milder frontal lesions may also have affected these cognitive functions. These clinical alterations are frequently under diagnosed in the clinical context.

On the other hand, small vessels in retina and brain share similar physiological and anatomical features. Retina offers a unique window to the study of cerebral micro vascular lesion, because of its accessibility and non-invasiveness through fundoscopy. Several studies [18-20] report that retinal micro vascular changes such as arteriolar narrowing, arteriovenous nicking, micro aneurysms, micro exudates and micro hemorrhages are strongly associated with subclinical [21-24] and clinical cerebrovascular damage. Agreeing with those reports, we found in our patient, several lesions, indicating an important degree of retinal small vessels injury associated with important silent cerebrovascular injuries observed on MRI.

Currently, SVD is considered a major health problem transcending the asymptomatic or subclinical stage [25-27]. Several studies report that SVD has a negative impact on the stroke prognosis and on functional recovery after stroke. Therefore, being able to identify these alterations in early stage is very important. This must necessarily be carried out through rational diagnostic alternatives, with simple and economical technologies that can be applied in medical practice. At this point, the quantitative EEG analysis combined with quantitative parameters of fundus alterations could provide predictive value information to identify those patients who require more sophisticated assessments and access to more complex and expensive diagnostic tools.

However, these results require further extensive research regarding the identification and mapping of specific EEG indices related to vascular damage, and quantitative methods of retinal parameters obtained from digital retinal photographs. This will allow us to evaluate the diagnostic efficiency of these methods in the prediction of subclinical cerebrovascular lesions in patients with vascular risk.

\section{References}

1. WHO. Global status report on non communicable diseases 2010. Geneva. 2010.

2. Mancia G, Fagard R, Narkiewicz K, Redon J, Zanchetti A, Bohm M, et al. 2013 ESH/ESC Guidelines for the management of arterial hypertension: the Task Force for the management of arterial hypertension of the European Society of Hypertension (ESH) and of the European Society of Cardiology (ESC). J Hypertens. 2013; 31: 1281-1357.

3. Lehmann MV, Schmieder RE. Remodeling of retinal small arteries in hypertension. Am J Hypertens. 2011; 24: 1267-1273.

4. Halford J, Sabau D, Drislane F, Tsuchida T, Sinha SR. American Clinical Neurophysiology Society Guideline 4: Recording Clinical EEG on Digital Media. J Clin Neurophysiol. 2016; 56: 261-265.

5. Pascual-Marqui RD, Michel CM, Lehmann D. Low resolution electromagnetic tomography: a new method for localizing electrical activity in the brain. Int J Psychophysiol. 1994; 18: 49-65.

6. Gouw AA, Seewann A, van der Flier WM, Barkhof F, Rozemuller AM, Scheltens $\mathrm{P}$, et al. Heterogeneity of small vessel disease: a systematic review of MRI and histopathology correlations. J Neurol Neurosurg Psychiatry. 2011; 82: 126-35.

7. Pantoni L. Cerebral small vessel disease: from pathogenesis and clinica characteristics to therapeutic challenges. Lancet Neurol. 2010; 9: 689-701.

8. Kearney-Schwartz A, Rossignol P, Bracard S, Felblinger J, Fay R, Boivin JM, et al. Vascular structure and function is correlated to cognitive performance and white matter hyperintensities in older hypertensive patients with subjective memory complaints. Stroke. 2009; 40: 1229-1236.

9. Henskens LH, van Oostenbrugge RJ, Kroon AA, Hofman PA, Lodder J, de Leeuw PW. Detection of silent cerebrovascular disease refines risk stratification of hypertensive patients. J Hypertens. 2009; 27: 846-853. 
10. Rothwell PM, Coull AJ, Silver LE, Fairhead JF, Giles MF, Lovelock CE, et al Population-based study of event-rate, incidence, case fatality, and mortality for all acute vascular events in all arterial territories (Oxford Vascular Study). Lancet. 2005 19; 366: 1773-17883.

11. Sehestedt T, Olsen $\mathrm{MH}$. Subclinical organ damage and cardiovascular risk prediction. Blood Press. 2010; 19: 132-139.

12. Currie G, Delles C. Use of Biomarkers in the Evaluation and Treatment of Hypertensive Patients. Curr Hypertens Rep. 2016; 18: 54

13. Moretti DV, Zanetti O, Binetti G, Frisoni GB. Quantitative EEG Markers in Mild Cognitive Impairment: Degenerative versus Vascular Brain Impairment. Int J Alzheimers Dis. 2012; 2012: 917537.

14. Moretti DV, Frisoni GB, Binetti G, Zanetti O. Anatomical Substrate and Scalp EEG Markers are correlated in Subjects with Cognitive Impairment and Alzheimer's disease. Front Psychiatry. 2011; 1: 152.

15. Sheorajpanday RV, Marien P, Weeren AJ, Nagels G, Saerens J, van Putten $\mathrm{MJ}$, et al. EEG in silent small vessel disease: sLORETA mapping reveals cortical sources of vascular cognitive impairment no dementia in the default mode network. J Clin Neurophysiol. 2013; 30: 178-187.

16. Nunez PL, Srinivasan R. A theoretical basis for standing and traveling brain waves measured with human EEG with implications for an integrated consciousness. Clin Neurophysiol. 2006; 117: 2424-2435.

17. Leech R, Sharp DJ. The role of the posterior cingulate cortex in cognition and disease. Brain. 2014; 137: 12-32.

18. Wong TY, McIntosh R. Systemic associations of retinal microvascular signs: a review of recent population-based studies. Ophthalmic Physiol Opt. 2005 25: 195-204.

19. Yatsuya H, Folsom AR, Wong TY, Klein R, Klein BE, Sharrett AR. Retina microvascular abnormalities and risk of lacunar stroke: Atherosclerosis Risk in Communities Study. Stroke. 2010; 41: 1349-1355.

20. Kim DH, Chaves $\mathrm{PH}$, Newman AB, Klein R, Sarnak MJ, Newton E, et al. Retinal microvascular signs and disability in the Cardiovascular Health Study. Arch Ophthalmol. 2012; 130: 350-356.

21. Cheung N, Mosley T, Islam A, Kawasaki R, Sharrett AR, Klein R, et al. Retinal microvascular abnormalities and subclinical magnetic resonance imaging brain infarct: a prospective study. Brain. 2010; 133: 1987-1993.

22. De Silva DA, Manzano JJ, Liu EY, Woon FP, Wong WX, Chang HM, et al. Retinal microvascular changes and subsequent vascular events after ischemic stroke. Neurology. 2011 30; 77: 896-903.

23. Wieberdink RG, Ikram MK, Koudstaal PJ, Hofman A, Vingerling JR, Breteler MM. Retinal vascular calibers and the risk of intracerebral hemorrhage and cerebral infarction: the Rotterdam Study. Stroke. 2010; 41: 2757-2761.

24. Wang JJ, Baker ML, Hand PJ, Hankey GJ, Lindley RI, Rochtchina E, et al. Transient ischemic attack and acute ischemic stroke: associations with retinal microvascular signs. Stroke. 2011; 42: 404-408.

25. Chutinet A, Rost NS. White matter disease as a biomarker for long-term cerebrovascular disease and dementia. Curr Treat Options Cardiovasc Med. 2014; 16: 292

26. Melkas S, Putaala J, Oksala NK, Pohjasvaara T, Oksala A, Kaste M, et al. Small-vessel disease relates to poor poststroke survival in a 12-year followup. Neurology. 2011 22; 76: 734-739.

27. Mott M, Pahigiannis K, Koroshetz W. Small blood vessels: big health problems: National Institute of Neurological Disorders and Stroke update. Stroke. 2014; 45: e257-e258.
Austin J Cerebrovasc Dis \& Stroke - Volume 4 Issue 4 - 2017

ISSN : 2381-9103 | www.austinpublishinggroup.com

Brown-Martínez et al. (C) All rights are reserved
Citation: Brown-Martínez M, Virués T, Valdés Y, González E, Fernández O, Hernández Z, et al. Quantitative Electroencephalographic Changes and Retinal Alterations in Subclinical Cerebrovascular Injury: A Case Report. Austin J Cerebrovasc Dis \& Stroke. 2017; 4(4): 1065 